\title{
Preparation of sulfonated reduced graphene oxide by radiation- induced chemical reduction of sulfonated graphene oxide
}

\author{
Chang-Hee Jung ${ }^{1}$, Ji-Hyun Hong ${ }^{1,2}$, Jin-Mook Jung ${ }^{1}$, In-Tae Hwang ${ }^{1}$, Chan-Hee Jung ${ }^{1, \star}$ and Jae-Hak Choi ${ }^{2, \star}$ \\ ${ }^{1}$ Research Division for Industry and Environment, Advanced Radiation Technology Institute, Korea Atomic Energy Research Insti- \\ tute, Jeongeup 580-185, Korea \\ ${ }^{2}$ Department of Polymer Science and Engineering, Chungnam National University, Daejeon 305-764, Korea
}

\section{Article Info \\ Received 26 August 2014 \\ Accepted 13 December 2014 \\ *Corresponding Author
E-mail: jch@kaeri.re.kr
jaehakchoi@cnu.ac.kr \\ Tel: $+82-63-570-3064$ \\ Open Access \\ DOI: http://dx.doi.org/ \\ 10.5714/CL.2015.16.1.041 \\ This is an Open Access article distributed under the terms of the Creative Commons Attribution Non-Commercial License (http://creativecommons.org/licenses/ by-nc/3.0/) which permits unrestricted non-commercial use, distribution, and reproduction in any medium, provided the original work is properly cited.}

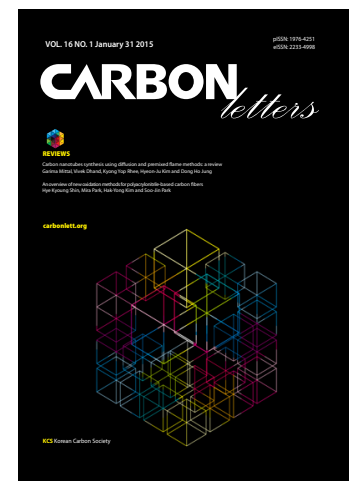

http://carbonlett.org

pISSN: 1976-4251

elSSN: 2233-4998

Copyright $\odot$ Korean Carbon Society

\begin{abstract}
We report the preparation of sulfonated reduced graphene oxide (SRGO) by the sulfonation of graphene oxide followed by radiation-induced chemical reduction. Graphene oxide prepared by the well-known modified Hummer's method was sulfonated with the aryl diazonium salt of sulfanilic acid. Sulfonated graphene oxide (SGO) dispersed in ethanol was subsequently reduced by $\gamma$-ray irradiation at various absorbed doses to produce SRGO. The results of optical, chemical, and thermal analyses revealed that SRGO was successfully prepared by $\gamma$-ray irradiation-induced chemical reduction of the SGO suspension. Moreover, the electrical conductivity of SRGO was increased up to $2.94 \mathrm{~S} / \mathrm{cm}$ with an increase of the absorbed dose.
\end{abstract}

Key words: sulfonated reduced graphene oxide, graphene oxide, sulfonation, reduction, $\gamma$-ray irradiation.

\section{Introduction}

Graphene has elicited great interest since it was discovered by Andre Geim and Konstantin Novoselov in 2004 [1,2]. On the basis of its unique electrical, optical, thermal, and mechanical properties it is desirable for a broad range of high-tech applications in flexible transparent electronic devices, supercapacitors, batteries, composites, and flexible transparent displays and sensors [3]. Top-down and bottom-up strategies, such as mechanical exfoliation of graphite, chemical reduction of graphene oxide (GO), unzipping of carbon nanotubes, chemical vapor deposition, and epitaxial growth, have been developed to produce graphene [4,5]. Among these strategies, the chemical reduction of GO is the most attractive owing to its low fabrication cost and capability of mass production [6]. In terms of the feasibility of this method, however, chemical reduction has been a critical issue, and it has been accomplished by various methods, including the use of chemical reducing agents, thermal and solvothermal treatment, electrochemical and photocatalytic reduction, and radiationinduced chemical reduction [7-9].

Radiation-induced chemical reduction is considered a desirable route for reducing GO, in terms of environmental friendliness, efficiency, cost, and scalability [10]. In this light, radiation-induced chemical reduction of GO suspensions in aqueous and non-aqueous solvents recently has been studied [11-13]. However, radiation-induced chemical reduction of $\mathrm{GO}$ with various functional groups has not yet been explored.

In this study, the preparation of sulfonated reduced graphene oxide (SRGO) by the sulfonation of GO followed by the irradiation of sulfonated graphene oxide (SGO) with $\gamma$-rays is described. The prepared SRGO has been characterized in terms of its optical, chemical, thermal, and electrical properties. 


\section{Experimental}

\subsection{Materials}

Graphite powder (SP-1) was supplied from Bay Carbon (Bay City, MI, USA). Concentrated sulfuric acid $\left(\mathrm{H}_{2} \mathrm{SO}_{4}\right)$, potassium peroxodisulfate $\left(\mathrm{K}_{2} \mathrm{~S}_{2} \mathrm{O}_{8}\right)$, phosphorus pentoxide $\left(\mathrm{P}_{2} \mathrm{O}_{5}\right)$, potassium permanganate $\left(\mathrm{KMnO}_{4}\right)$, hydrogen peroxide $\left(\mathrm{H}_{2} \mathrm{O}_{2}\right)$, hydrochloric acid $(\mathrm{HCl}, 0.1 \mathrm{~N})$, ethanol $(\mathrm{EtOH})$, sulfanilic acid $\left(\mathrm{C}_{6} \mathrm{H}_{7} \mathrm{NO}_{3} \mathrm{~S}\right)$, sodium hydroxide $(\mathrm{NaOH})$, and sodium nitrite $\left(\mathrm{NaNO}_{2}\right)$ were purchased from Aldrich Company. All chemicals in this study were used as received.

\subsection{Preparation of SGO by aryl diazonium reaction}

A $20 \mathrm{~mL}$ GO suspension $(10 \mathrm{mg} / \mathrm{mL})$ in deionized water prepared from graphite powder by the well-known modified Hummer's method was added to a three-necked round flask $[11,14]$. To prepare an aryl diazonium salt solution, sulfanilic acid $(500 \mathrm{mg})$ and sodium nitrate $(200 \mathrm{mg})$ were dissolved in $10 \mathrm{~mL}$ of $2 \mathrm{wt} \% \mathrm{NaOH}$ solution at $50^{\circ} \mathrm{C}$. The resulting homogenous solution was added into $20 \mathrm{~mL}$ of $0.1 \mathrm{~N} \mathrm{HCl}$ solution in an ice bath with stirring [15]. After reaction for $15 \mathrm{~min}$, the resulting aryl diazonium salt solution was added dropwise into a three-necked round flask containing a $20 \mathrm{~mL}$ GO suspension and was vigorously stirred for $4 \mathrm{~h}$ in an ice bath. To obtain SGO, the resulting solution was centrifuged and rinsed with deionized water more than five times. The obtained SGO was readily dispersed in $\mathrm{EtOH}$ at a cogeneration of $1 \mathrm{mg} / \mathrm{mL}$.

\subsection{Preparation of SRGO by $Y$-ray irradiation- induced chemical reduction}

To prepare SRGO, $80 \mathrm{~mL}$ aliquots of as-prepared SGO (1 mg/ $\mathrm{mL}$ ) solution in EtOH were poured into $100 \mathrm{~mL}$ glass bottles, which were then sealed with rubber sept, and finally purged with nitrogen gas to eliminate the existing oxygen. The bottles containing the SGO solution were irradiated with $\gamma$-rays at room temperature from a ${ }^{60} \mathrm{Co}$ source at the Advanced Radiation Technology Institute (ARTI) of the Korea Atomic Energy Research Institute (KAERI). The total absorbed doses ranged from 10 to $50 \mathrm{kGy}$, and the dose rate was $5 \mathrm{kGy} / \mathrm{h}$. The resulting solution was then isolated by filtration through a $0.45 \mu \mathrm{m}$ polytetrafluoroethylene membrane filter and dried in a vacuum oven at $60^{\circ} \mathrm{C}$ for $24 \mathrm{~h}$.

\subsection{Characterization}

Ultraviolet-visible (UV-vis) spectra were recorded on a UVVis spectrophotometer (Scinco S-3100, Korea). A Fourier transform infrared (FT-IR) spectroscopic analysis was performed using an FT-IR spectrometer (Varian 640, Australia). An X-ray photoelectron spectroscopic analysis (XPS) was carried out using a MultiLab 2000 X-ray photoelectron spectroscope (Thermo Electron Corporation, England). A thermogravimetric analysis (TGA) was conducted on a Q600 analyzer (TA Instruments, USA) in a temperature range of $50^{\circ} \mathrm{C}$ to $600^{\circ} \mathrm{C}$ at a heating rate of $5^{\circ} \mathrm{C} / \mathrm{min}$ under a nitrogen atmosphere. The electrical conductivities of $100 \mathrm{~nm}$-thick SRGO films measured with an AlphaStep IQ surface profiler (KLA Tencor, USA) were measured through a MCP-T610 four-point probe conductivity measurement system (Misubishi LORESTA-GP).

\section{Results and Discussion}

The optical properties of the GO, SGO, and SRGO samples prepared at various absorbed doses were investigated through a UV-vis analysis, and the results are shown in Fig. 1. The GO and SGO specimens exhibited an identical absorption peak at $230 \mathrm{~nm}$, indicating that the optical properties of the GO were not significantly affected by the aryl diazonium reaction-based sulfonation. On the other hand, the absorption peak of all SRGO samples prepared at the given absorbed doses was present at a longer wavelength of $265 \mathrm{~nm}$ in comparison to that of the SGO [16]. In addition, as shown in the inset (Fig. 1), the brown solution of the SGO in EtOH was transformed to a dark color after $\gamma$-ray irradiation. This indicates that SRGO was successfully prepared by $\gamma$-ray irradiation-induced restoration of the $\pi$-conjugation system in the SGO.

The chemical structures of the GO, SGO, and SRGO samples

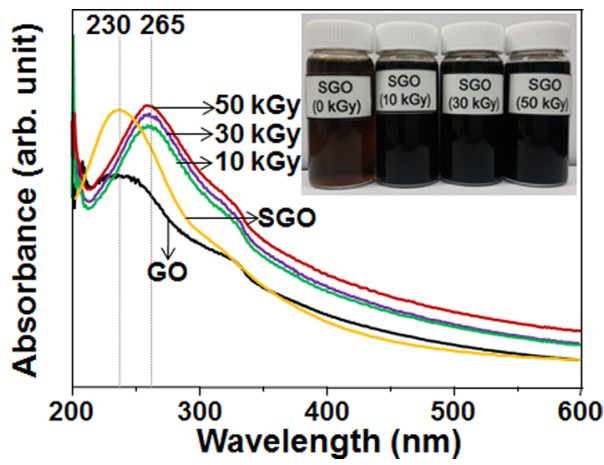

Fig. 1. UV-visible absorption spectra of graphene oxide (GO), sulfonated GO (SGO), and sulfonated reduced GO (SRGO) samples prepared at absorbed doses of 10, 30, and $50 \mathrm{kGy}$. The inset shows the photographs of SGO in EtOH before and after $\gamma$-ray irradiation at absorbed doses of 10, 30, and $50 \mathrm{kGy}$.

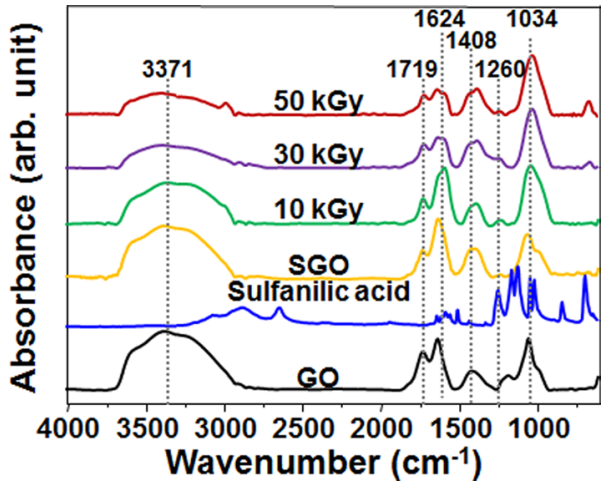

Fig. 2. Fourier transform infrared spectra of graphene oxide (GO), sulfanilic acid, sulfonated GO (SGO), and sulfonated reduced GO prepared at absorbed doses of 10,30, and $50 \mathrm{kGy}$. 


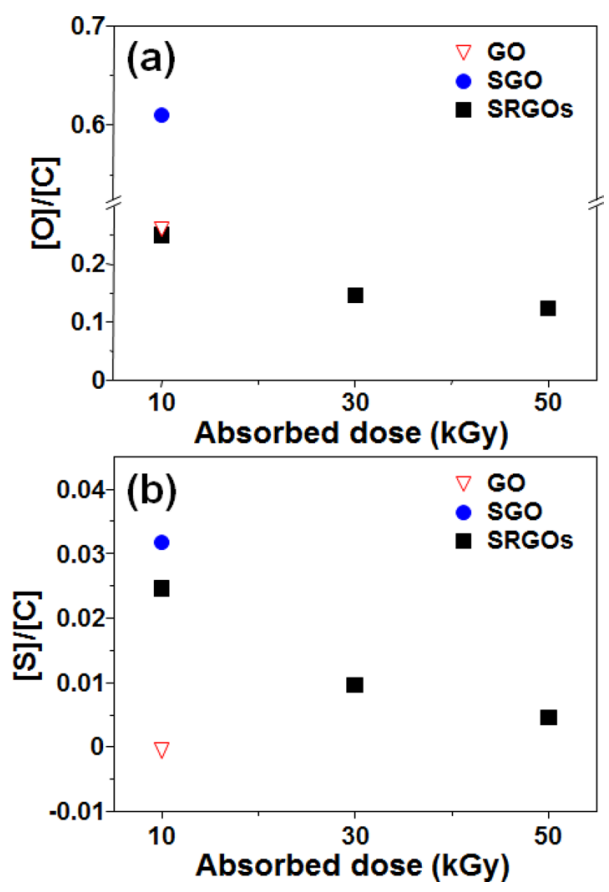

Fig. 3. $[O] /[C]$ (a) and $[S] /[C]$ atomic ratios (b) of graphene oxide (GO), sulfonated $\mathrm{GO}(\mathrm{SGO})$, and sulfonated reduced $\mathrm{GO}$ (SRGO) prepared at absorbed doses of 10,30, and $50 \mathrm{kGy}$, determined by an X-ray photoelectron spectroscopic analysis.

prepared at various absorbed doses were investigated by a FT-IR analysis, and the results are shown in Fig. 2. The characteristic peaks of the $\mathrm{GO}$ were observed at $3371(-\mathrm{OH}), 1719(\mathrm{C}=\mathrm{O}$ in carboxylic acid), 1624 (absorbed $\mathrm{H}_{2} \mathrm{O}$ or aromatic $\mathrm{C}=\mathrm{C}$ ), 1408 $(\mathrm{C}-\mathrm{OH})$, and $1034(\mathrm{C}-\mathrm{O}) \mathrm{cm}^{-1}$, respectively. In the SGO spectrum, the characteristic peak corresponding to the chemical structure of sulfanilic acid was clearly observed at $1260 \mathrm{~cm}^{-1}$ $(\mathrm{O}=\mathrm{S}=\mathrm{O})$, although the peaks for the amide and phenyl groups hidden by the GO could not be observed [17]. On the other hand, the oxygen-containing functionalities such as $-\mathrm{OH}, \mathrm{C}=\mathrm{O}$, and $\mathrm{C}-\mathrm{OH}$ were reduced with an increase in the absorbed dose [18]. Furthermore, the $[\mathrm{O}] /[\mathrm{C}]$ and $[\mathrm{S}] /[\mathrm{C}]$ atomic ratios of the $\mathrm{GO}$, $\mathrm{SGO}$, and SRGO samples obtained through an XPS analysis revealed that the $[\mathrm{O}] /[\mathrm{C}]$ and $[\mathrm{S}] /[\mathrm{C}]$ ratios of the SGO were higher than those of the GO, confirming successful sulfonation, and those of the SRGO decreased with an increase in the absorbed dose in comparison to those of the SGO [19]. This implies that SGO was successfully prepared by the sulfonation of GO, and the resulting SGO suspensions in EtOH were effectively reduced by $\gamma$-ray irradiation-induced deoxygenation, resulting in the formation of SRGO.

The thermal decomposition curves of the GO, SGO, and SRGO samples prepared at various absorbed doses are shown in Fig. 4. As shown in the GO and SGO curves, the SGO showed a similar tendency to the characteristic decomposition curves of the GO owing to the small extent of sulfonation. On the other hand, the SRGO exhibited a dose-dependent decrease of its weight in a temperature range of $150^{\circ} \mathrm{C}$ to $250^{\circ} \mathrm{C}$ in comparison to that of the SGO, and this is ascribed to the elimination of thermally-liable oxygen containing functionalities during $\gamma$-ray

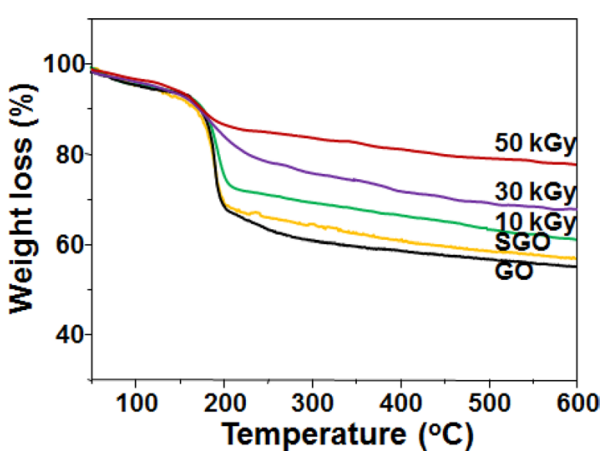

Fig. 4. Thermogravimetric analysis curves of graphene oxide (GO), sulfonated $\mathrm{GO}(\mathrm{SGO})$, and sulfonated reduced $\mathrm{GO}$ prepared at absorbed doses of 10, 30, and $50 \mathrm{kGy}$.

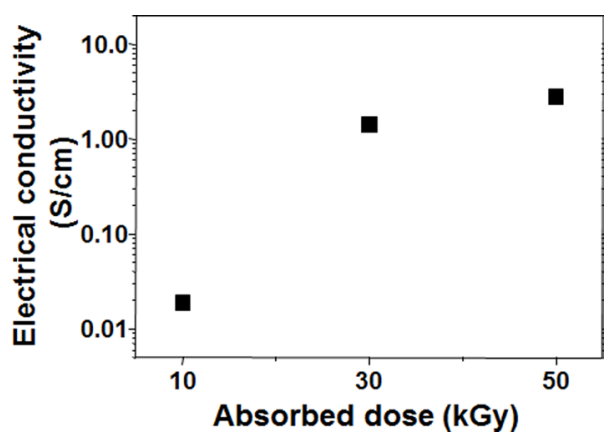

Fig. 5. Electrical conductivity of sulfonated reduced graphene oxide prepared at absorbed doses of 10,30, and $50 \mathrm{kGy}$.

irradiation [20].

The electrical conductivities of the SRGO samples prepared at various absorbed doses were measured using a four-point probe, and the results are shown in Fig. 5. The electrical conductivities of GO and SGO could not be obtained in this measurement system, the lowest limit of which is $10^{-7} \mathrm{~S} / \mathrm{cm}$. On the other hand, the electrical conductivity of the SRGO was increased up to $2.94 \mathrm{~S} / \mathrm{cm}$ as the absorbed dose was increased. It was thus confirmed that SRGO was successfully produced by $\gamma$-ray irradiation-induced reduction of SGO.

\section{Conclusion}

The preparation of functionalized graphene (SRGO) by the sulfonation of GO followed by $\gamma$-ray irradiation-induced chemical reduction was successfully demonstrated in this work. The results of UV, FT-IR, XPS, and TGA analyses revealed that SGO suspensions in EtOH prepared by the sulfonation of GO with aryl diazonium salt were successfully reduced to SRGO by $\gamma$-ray irradiation-induced deoxygenation, and the optical, chemical, and thermal properties of the resulting SRGO were dependent on the absorbed doses. Furthermore, the electrical conductivity of the SRGO was increased up to $2.94 \mathrm{~S} / \mathrm{cm}$ with an increase in the absorbed dose. This method can be used in the mass-production of SRGO suitable for various applications including composites, coating, paints/inks, biomaterials, and electronic materials. 


\section{Acknowledgements}

This work was supported by a National Research Foundation of Korea (NRF) grant funded by the Korean government (MSIP) (No. 2013M2A2A6023510 and 2014M2A2A6045042).

\section{References}

[1] Novoselov KS, Geim AK, Morozov SV, Jiand D, Zhang Y, Dubonos SV, Grigorieva IV, Firsov AA. Electric field effect in atomically thin carbon films. Science, 306, 666 (2004). http://dx.doi. org/10.1126/science.1102896.

[2] Geim AK, Novoselov KS. The rise of graphene. Nat Mater, 6, 183 (2007). http://dx.doi.org/10.1038/nmat1849.

[3] Novoselov KS, Fal'ko VI, Colombo L, Gellert PR, Schwab MG, Kim K. A roadmap for graphene. Nature, 490, 192 (2012). http:// dx.doi.org/10.1038/nature11458.

[4] Edwards RS, Coleman KS. Graphene synthesis: relationship to applications. Nanoscale, 5, 38 (2013). http://dx.doi.org/10.1039/ c2nr32629a.

[5] Eigler S, Hirsch A. Chemistry with graphene and graphene oxide: challenges for synthetic chemists. Angew Chem Int Ed, 53, 7720 (2014). http://dx.doi.org/10.1002/anie.201402780.

[6] Pei S, Cheng HM. The reduction of graphene oxide. Carbon, 50, 3210 (2012). http://dx.doi.org/10.1016/j.carbon.2011.11.010.

[7] Gengler RYN, Spyrou K, Rudolf P. A roadmap to high quality chemically prepared graphene. J Phys D, 43, 374015 (2010). http:/ dx.doi.org/10.1088/0022-3727/43/37/374015.

[8] Chua CK, Pumera M. Chemical reduction of graphene oxide: a synthetic chemistry viewpoint. Chem Soc Rev, 43, 291 (2014). http://dx.doi.org/10.1039/c3cs60303b.

[9] Zhang B, Li L, Wang Z, Xie S, Zhang Y, Shen Y, Yu M, Deng B, Huang Q, Fan C, Li J. Radiation induced reduction: an effective and clean route to synthesize functionalized graphene. J Mater Chem, 22, 7775 (2012). http://dx.doi.org/10.1039/c2jm16722k.

[10] Zhang Y, Ma HL, Zhang Q, Peng J, Li J, Zhai M, Yu ZZ. Facile synthesis of well-dispersed graphene by $\gamma$-ray induced reduction of graphene oxide. J Mater Chem, 22, 13064 (2012). http://dx.doi. org/10.1039/c2jm32231e.
[11] Jung CH, Park YW, Hwang IT, Go YJ, Na SI, Shin K, Lee JS, Choi JH. Eco-friendly and simple radiation-based preparation of graphene and its application to organic solar cells. J Phys D, 47, 015105 (2014). http://dx.doi.org/10.1088/0022-3727/47/1/015105.

[12] Li J, Zhang B, Li L, Ma H, Yu M, Li J. $\gamma$-ray irradiation effects on graphene oxide in an ethylenediamine aqueous solution. Radiat Phys Chem, 94, 80 (2014). http://dx.doi.org/10.1016/j. radphyschem.2013.06.029.

[13] Flyunt R, Knolle W, Kahnt A, Prager A, Lotnyk A, Malig J, Guldi $\mathrm{D}$, Abel B. Mechanistic aspects of the radiation-chemical reduction of graphene oxide to graphene-like materials. Int J Radiat Biol, 90, 486 (2014). http://dx.doi.org/10.3109/09553002.2014.907934.

[14] Hummers WS, Offeman RE. Preparation of graphitic oxide. J Am Chem Soc, 80, 1339 (1958). http://dx.doi.org/10.1021/ ja01539a017.

[15] Ravikumar, Scott K. Freestanding sulfonated graphene oxide paper: a new polymer electrolyte for polymer electrolyte fuel cells. Chem Commun, 48, 5584 (2012). http://dx.doi.org/10.1039/ c2cc31771k

[16] Jung JM, Jung CH, Oh MS, Hwang IT, Jung CH, Shin K, Hwang J, Park SH, Choi JH. Rapid, facile, and eco-friendly reduction of graphene oxide by electron beam irradiation in an alcohol-water solution. Mater Lett, 126, 151 (2014). http://dx.doi.org/10.1016/j. matlet.2014.04.059

[17] Yu DS, Kuila T, Kim NH, Khanra P, Lee JH. Effects of covalent surface modifications on the electrical and electrochemica properties of graphene using sodium 4-aminoazobenzene-4'-sulfonate. Carbon, 54, 310 (2013). http://dx.doi.org/10.1016/j.carbon.2012.11.043.

[18] Hu C, Liu Y, Yang Y, Cui J, Huang Z, Wang Y, Yang L, Wang H, Xiao Y, Rong J. One-step preparation of nitrogen-doped graphene quantum dots from oxidized debris of graphene oxide. J Mater Chem B, 1, 39 (2013). http://dx.doi.org/10.1039/c2tb00189f.

[19] Pham VH, Dang TT, Singh K, Hur SH, Shin EW, Kim JS, Lee MA, Baeck SH, Chung JS. A catalytic and efficient route for reduction of graphene oxide by hydrogen spillover. J Mater Chem A, 1, 1070 (2013). http://dx.doi.org/10.1039/c2ta00249c.

[20] Jang J, Pham VH, Hur SH, Chung JS. Dispersibility of reduced alkylamine-functionalized graphene oxides in organic solvents. J Colloid Interface Sci, 424, 62 (2014). http://dx.doi.org/10.1016/j. jcis.2014.03.018. 